Journal Of Al-Azhar University Engineering Sector

Vol. 14, No. 50, January, 2019, 409-421

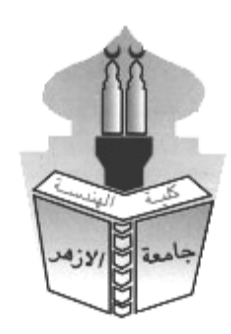

\title{
MONITORING SUSTAINABILITY APPLICATIONS IN THE PLANNING OF INTERNATIONAL EXPO EXHIBITIONS (CASE STUDY EXPO MILAN 2015)
}

\author{
Hassan Abdullah Kanani \\ Ph.D - Faculty of Architecture and Planning - King Saud University
}

\begin{abstract}
:
The concept of achieving sustainable development began in the early 1970s when it was observed that there was a great shortage of non-renewable natural resources. In 1980, the International Union for the Protection of the Natural Environment set the first strategy for global conservation. In 1983, And development in the study of the problems of environment and development on the planet, and in the first conference held for the land in the city of Rio de Janeiro in 1992 was focused on the future of future generations and their right to obtain energy suited to their needs in the future. Since then, sustainab`1ility has become an increasing priority for construction projects. It is well known that construction and operation of buildings has a direct and indirect impact on the environment surrounding these buildings. The exhibition is one of the most important international events in terms of economic and cultural impact, attracting millions of visitors from all over the world. It is held every 5 years and has a legacy of buildings. Where the study of the public site and the distribution of green spaces and water bodies, power generation and disposal of waste in addition to studying the legacy of the project and how to achieve the maximum benefit from the project after the end of the research and concluded that the exhibition is a clear example to take into account the principles of sustainability in the planning and design elements For different.

Key words Expo / Sustainability / Sustainable Development / Sustainable Buildings / Sus tainable Design Principles

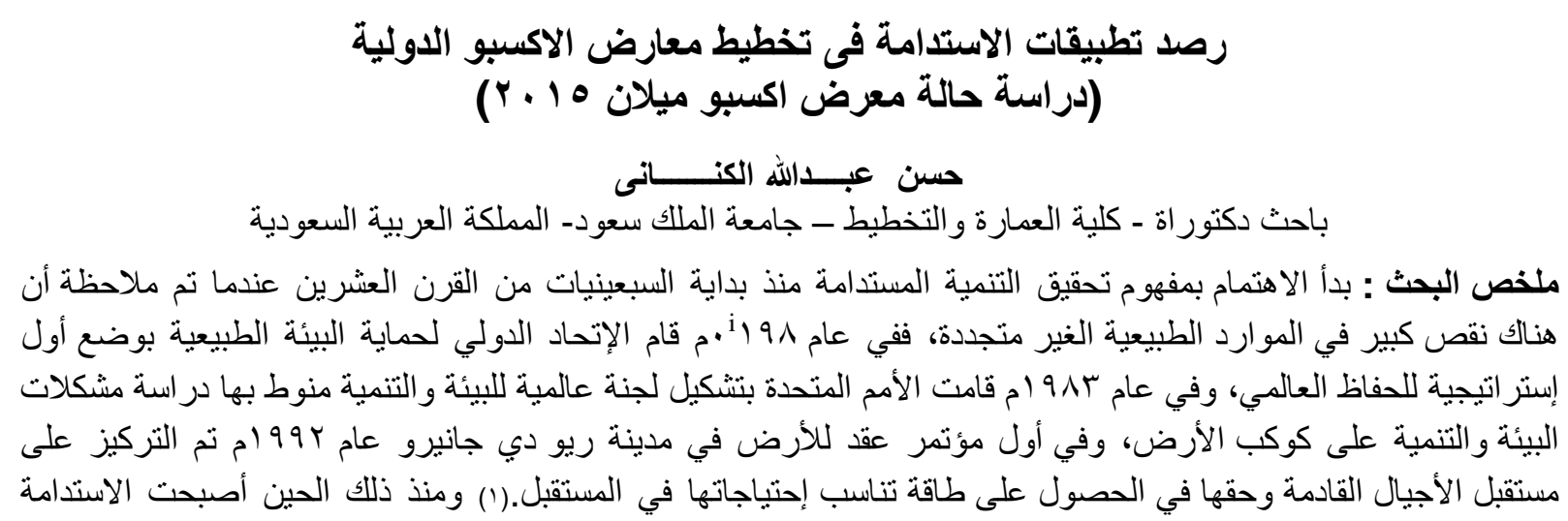


أولوية متز ايدة لمشاريع البناء، ولا يخفى على أحد أن بناء المباني وتثغيلها له تأثير كبير مباثر وغير مباثر على البيئة

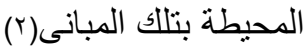

ولان معارض 》اإكسبو الدوليةها أ تعد حد أكبر الفعاليات العالمية من حيث التأثير الاقتصادي والثقافي حيث تستقطب ملايين الزوار من مختلف دول العالم، وتقام كل 5أعوام ولها ارث من المبانى كان لابد من مراع العاة مباد مبادئ التصميم المستدام من هنا

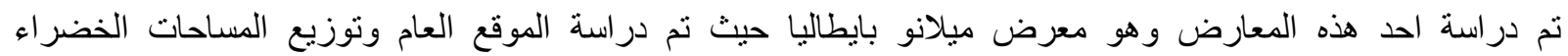

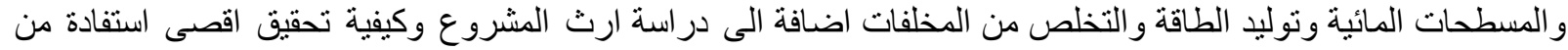

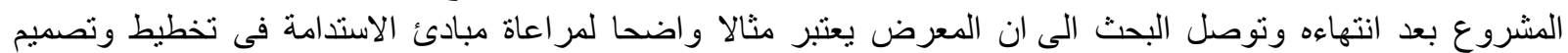

عناصره المختلفة.

الكلمات الدالة : اكسبو / الاستدامة / التتمية المستدامة / المبانى المستدامة/ مبادئ التصميم المستدام

مقدمة :

يعود الاهتمام بتحقيق الاستدامة فى المبانى الى اواخر القرن العشرين بسبب ظهور مشكلات الطاقة والمياه وذلك بهدف

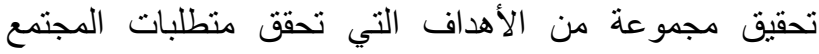

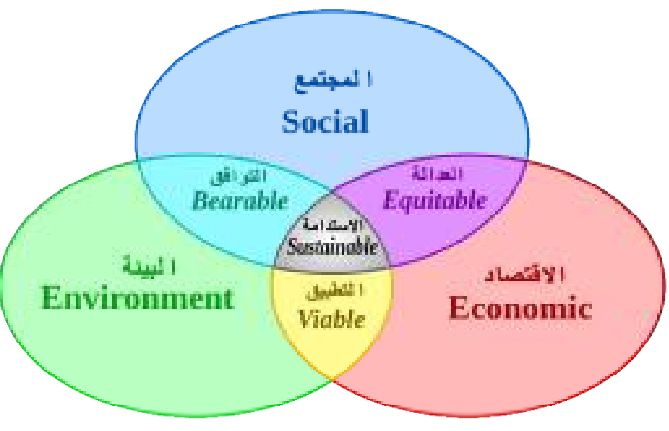

شكل ( ) يوضح الأبعاد الرئيسية للتنمية المستدامة

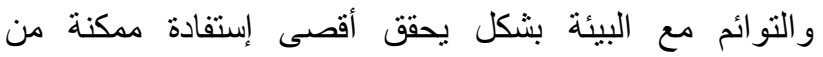

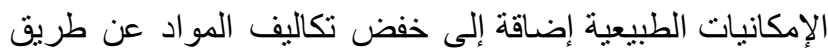
إعادة تذوير ها بشكل صحيح

فالاستدامة هي مصطلح بيئي يصف كيف تبر تبقى النظم الحيوية

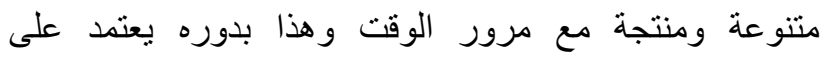

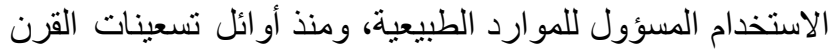

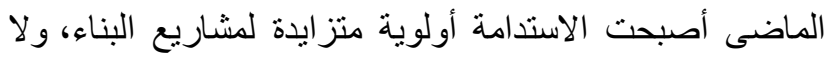

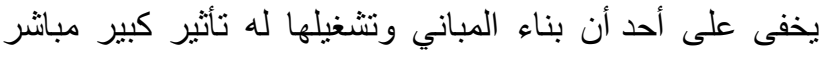

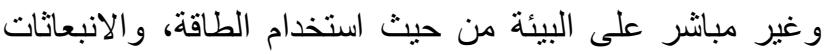

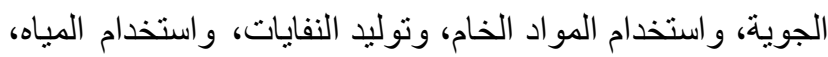

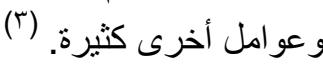

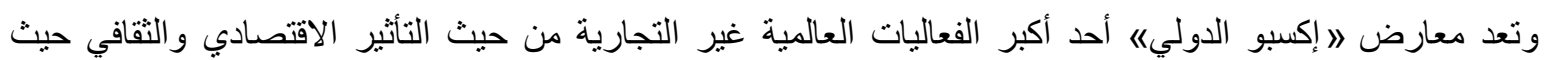

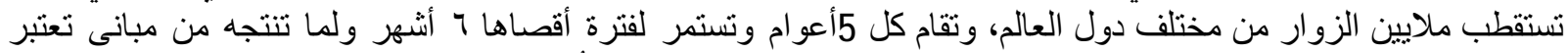

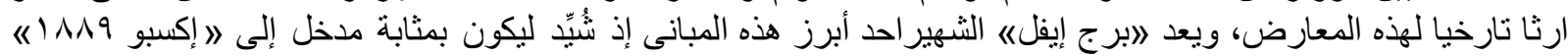

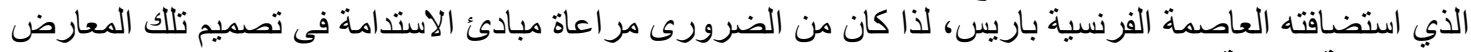

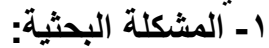

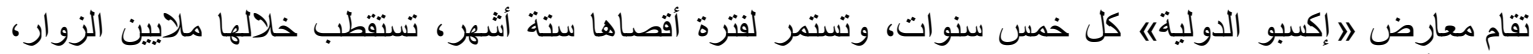

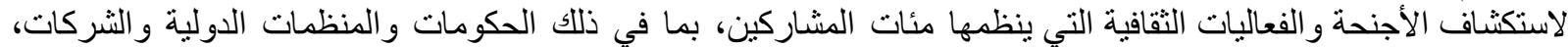

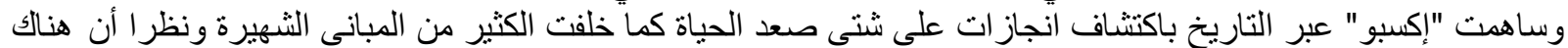

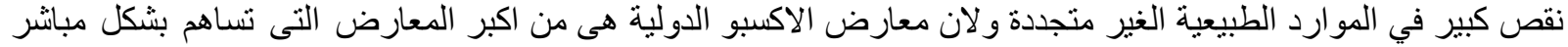

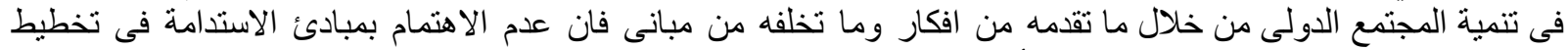

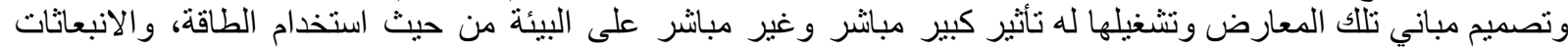

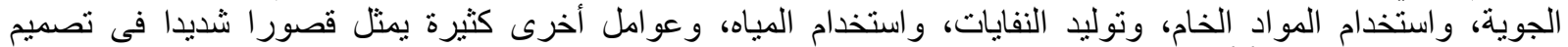

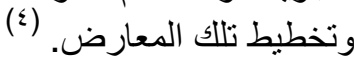

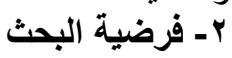


يفترض البحث بأن القائمين على تصميم وتخطيط تلك المعارض الدولية قد وضعو ا موضوع الاستدامة والتنمية المستدامة

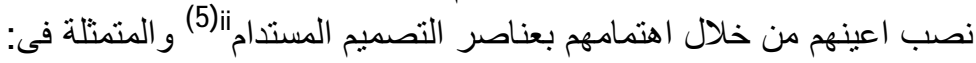
- تحسين إستخدام الطاقة.

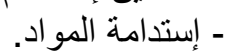
- تحسين ممارسات التشغيل و الصيانة.

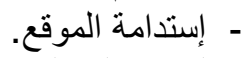
- م الحفظ على المبياه. - تعزيز جودة البيئة الداخلية.

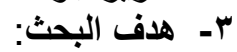

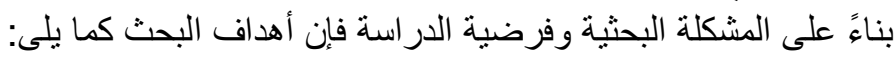

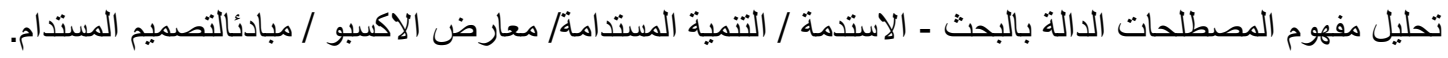

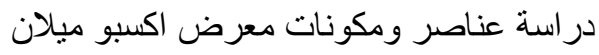
التعرف على مدى تحقيق المعرض لمبادئ الاستدامة المبنان ع - منهج البحث

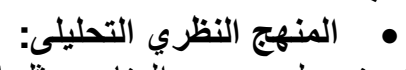

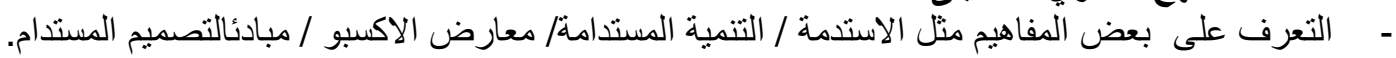

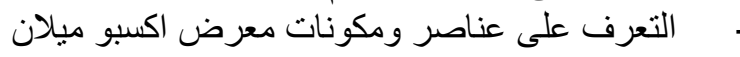

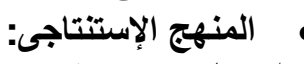

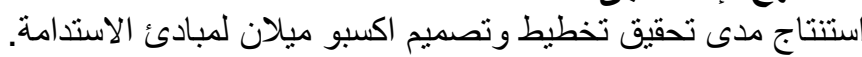

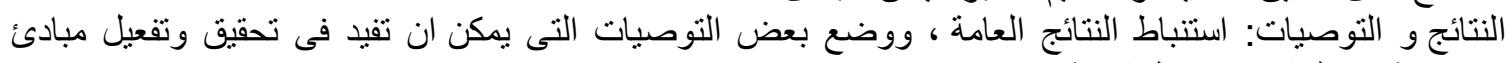
الاستدامة فى المشروعات المشات المشابهة.

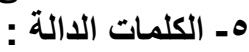

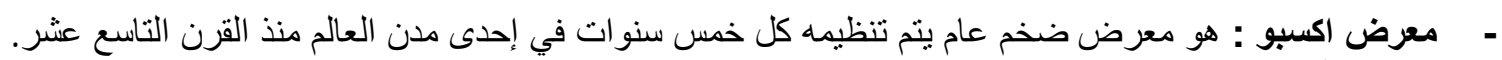

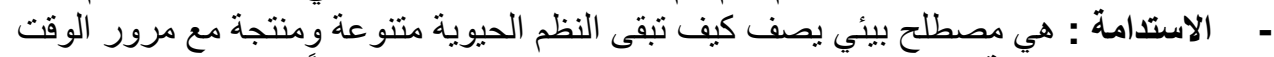

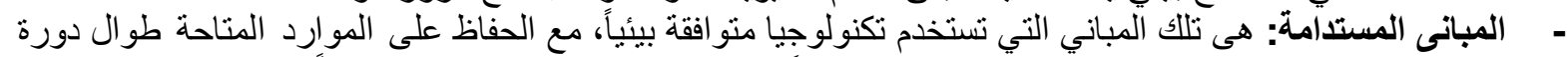

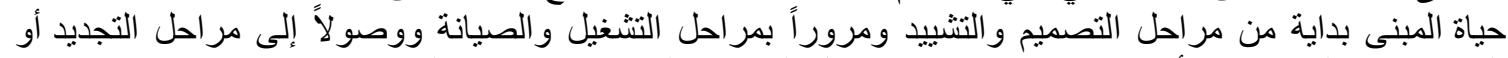

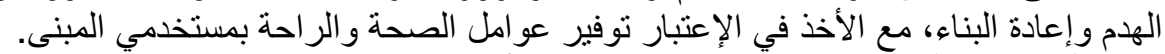

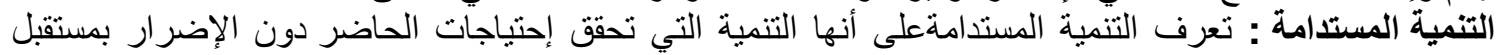
الأجيال القادمة التمبن

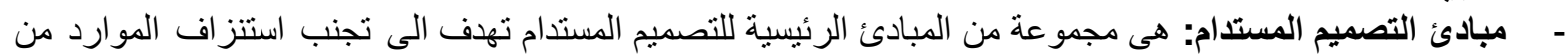

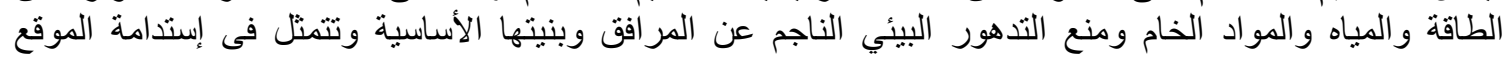

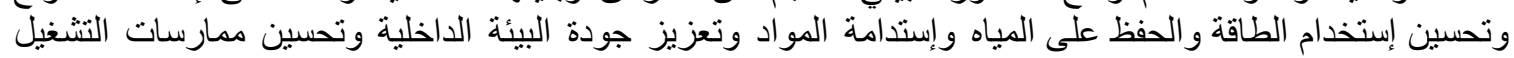

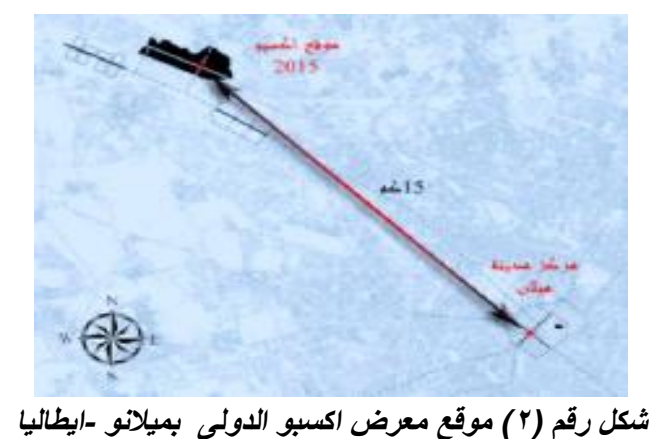

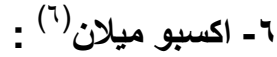
هو معرض عالمي عقد في مدينة مبلانو في إيطاليافى الفترة

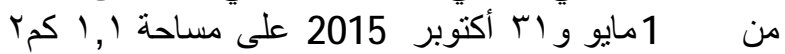
وقام بتنظيمه المكتب الدولى للمعارض BIE - Bureau International des Expositions" "Feeding the Planet, Energy الطاقة من أجل الحنان وشارك فى المعرض 0ـا أدولة وزار المعرض for Life"

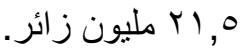

شكل رقم (r) موقع معرض اكسبو الدولى بميلانو -ايطاليا

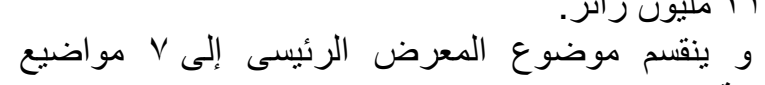
ا ـ العلم لسلامة و أمن و جودة الغذاء

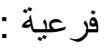
r ـ الإبتكار فى توريد الأغذية الزراعية 


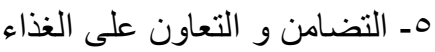

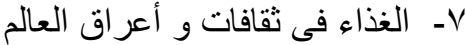

$$
\begin{aligned}
& \text { ك- تكنولوجيا الزراعة و التنوع البيولوجى } \\
& \text { ع ـ التثقيف الغذائى الزي } \\
& \text { 7- الغذاء من أجل أنماط حياة أفضل }
\end{aligned}
$$

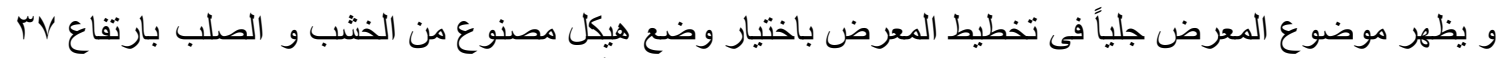
م على شكل شجرة تنمو ( شجرة الحياة - Tree of Life ) في أحد مداخل فلى المعرض من الرئيسية بمحور كاردو

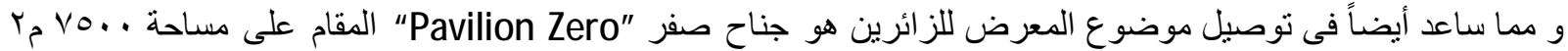

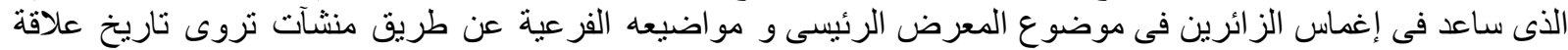

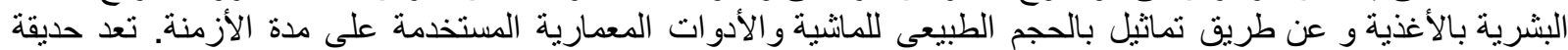

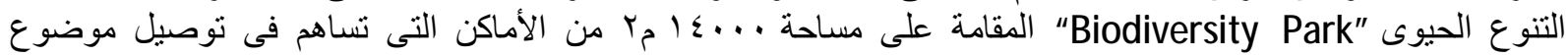

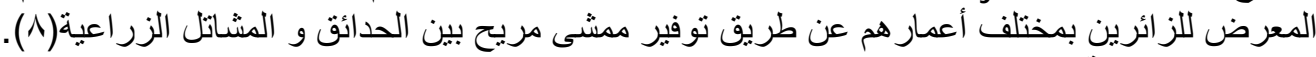

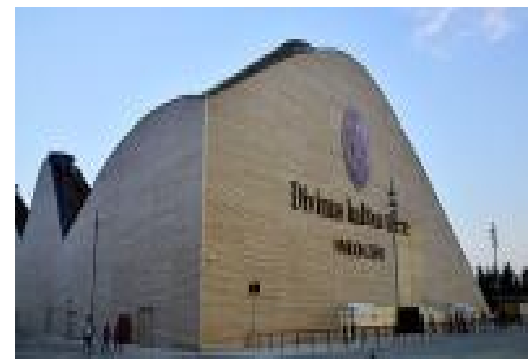

شكل رقم (0) جناح صفر

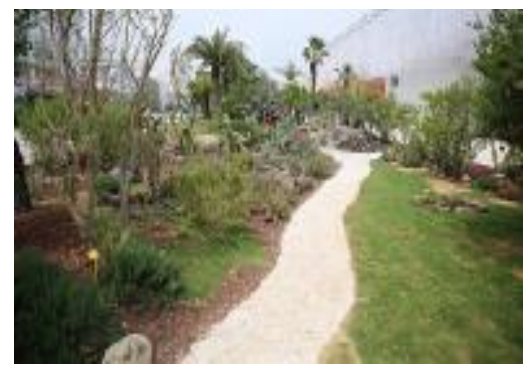

شكل رقم (๕) حديقة التنوع الحيوى

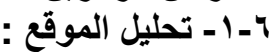

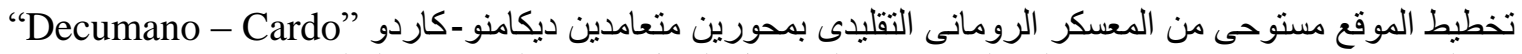

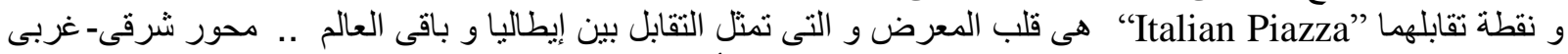

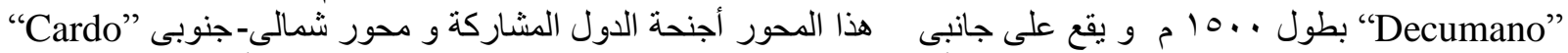

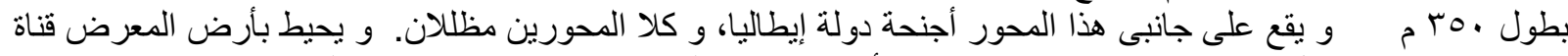

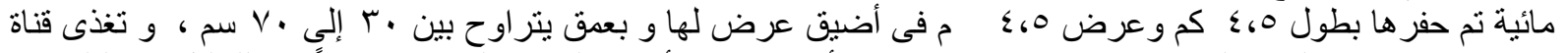
"Villoresi"

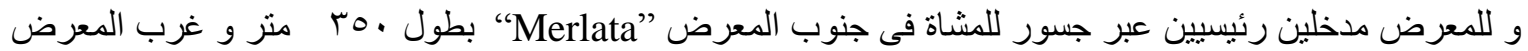
الضوضاء.

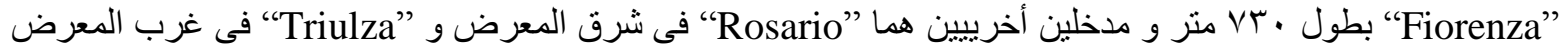


تبتوع مبانى المعرض ما بين أجنحة الدول المشاركة "Pavilions" و أجنحة زر اعة و أغذية المناطق المختلفة

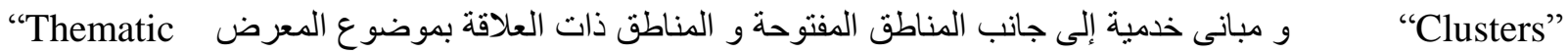

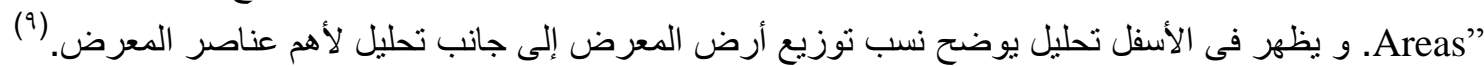
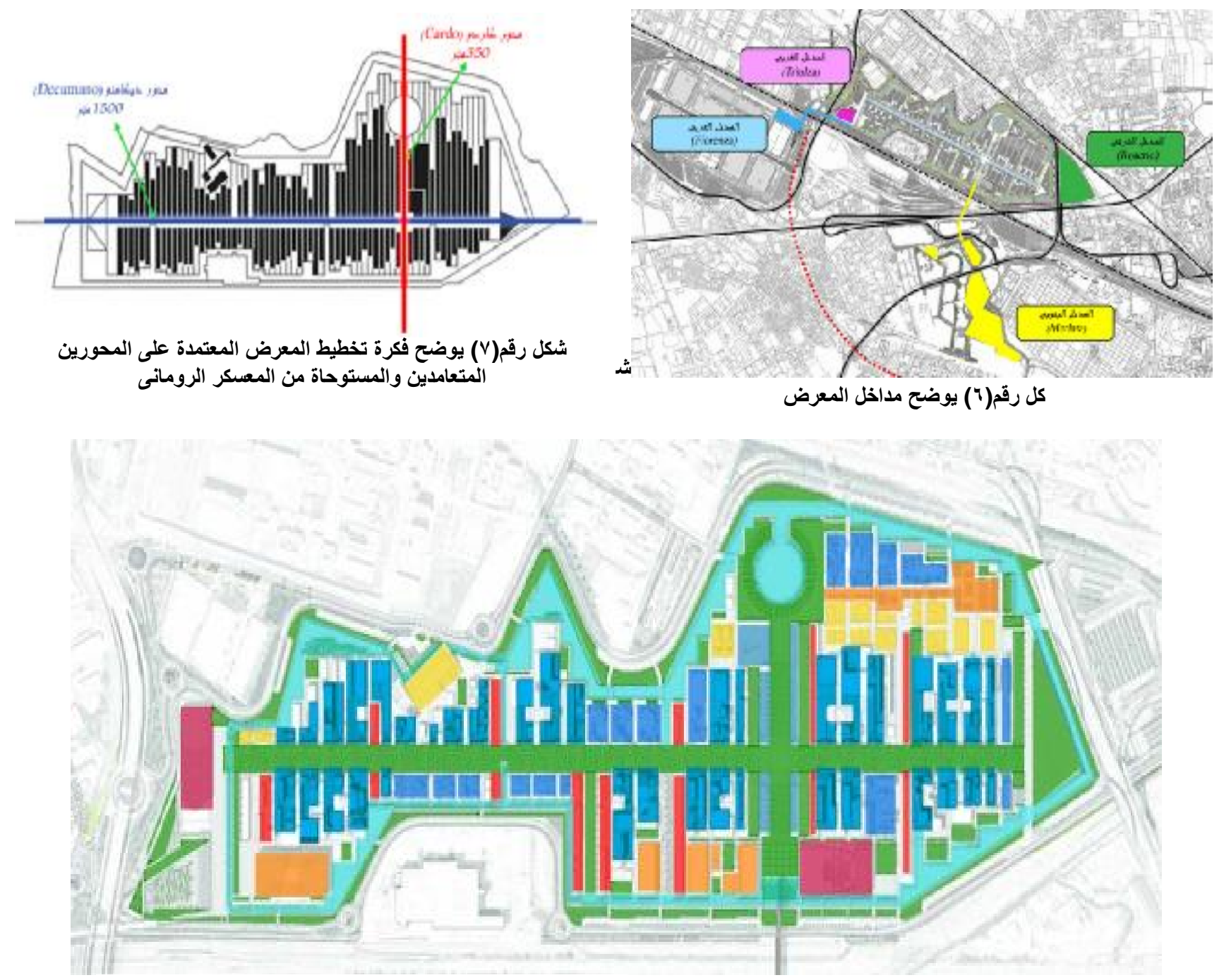

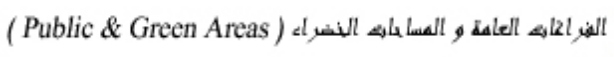

$$
\text { المشارعهون الل سميون (OP) }
$$

(Perimeter Roadways ) الشواري المبريل

(Water Canal )

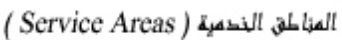

شكل رقم (1 ) يوضح استعمالات المعرض المختلفة ونسبة كلا منها

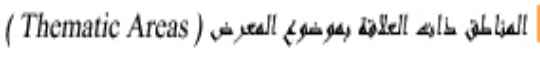

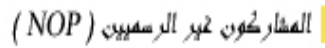

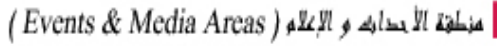

(المسانل ل Access 


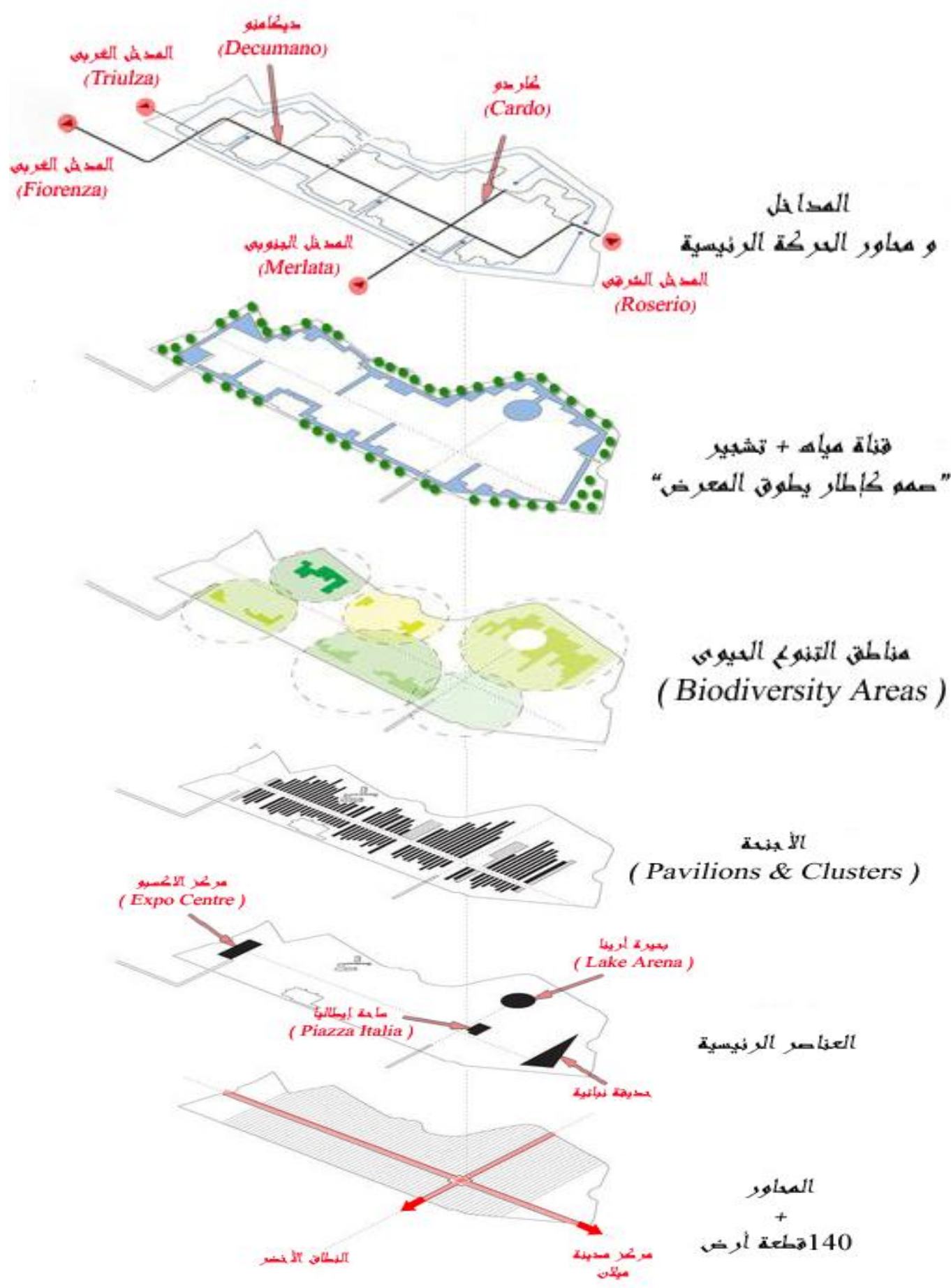

شكل رقم (9 ) تحليل لموقع المعرض 


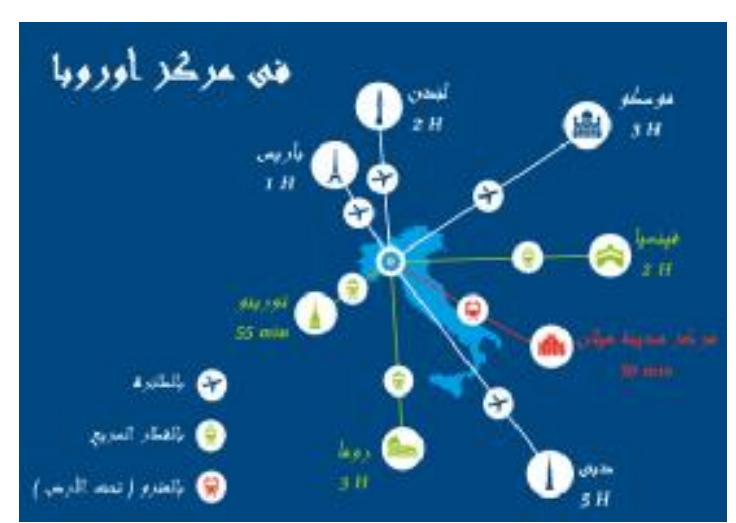

شكل رقم(10) موقع مدينة ميلان فى مركز اوربا

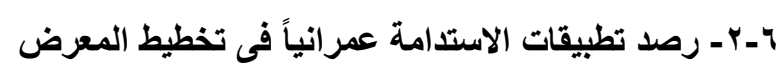

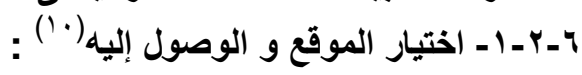

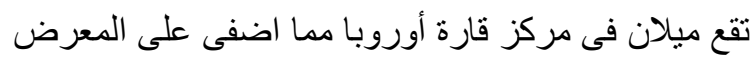

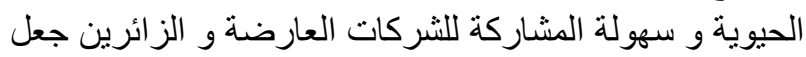

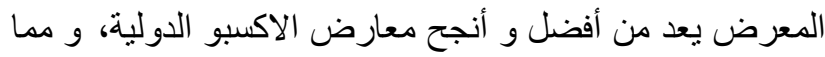

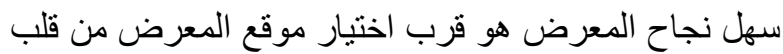

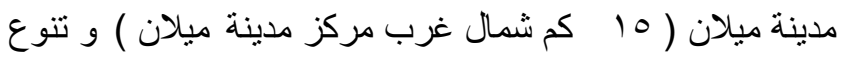

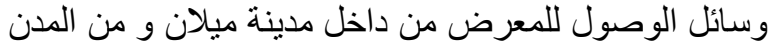

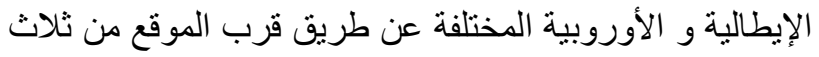
مطارات و هى ( Malpensa, Linate \& Orio al Serio)،

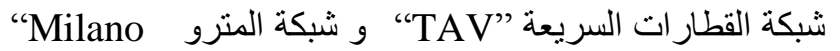
Underground Network"

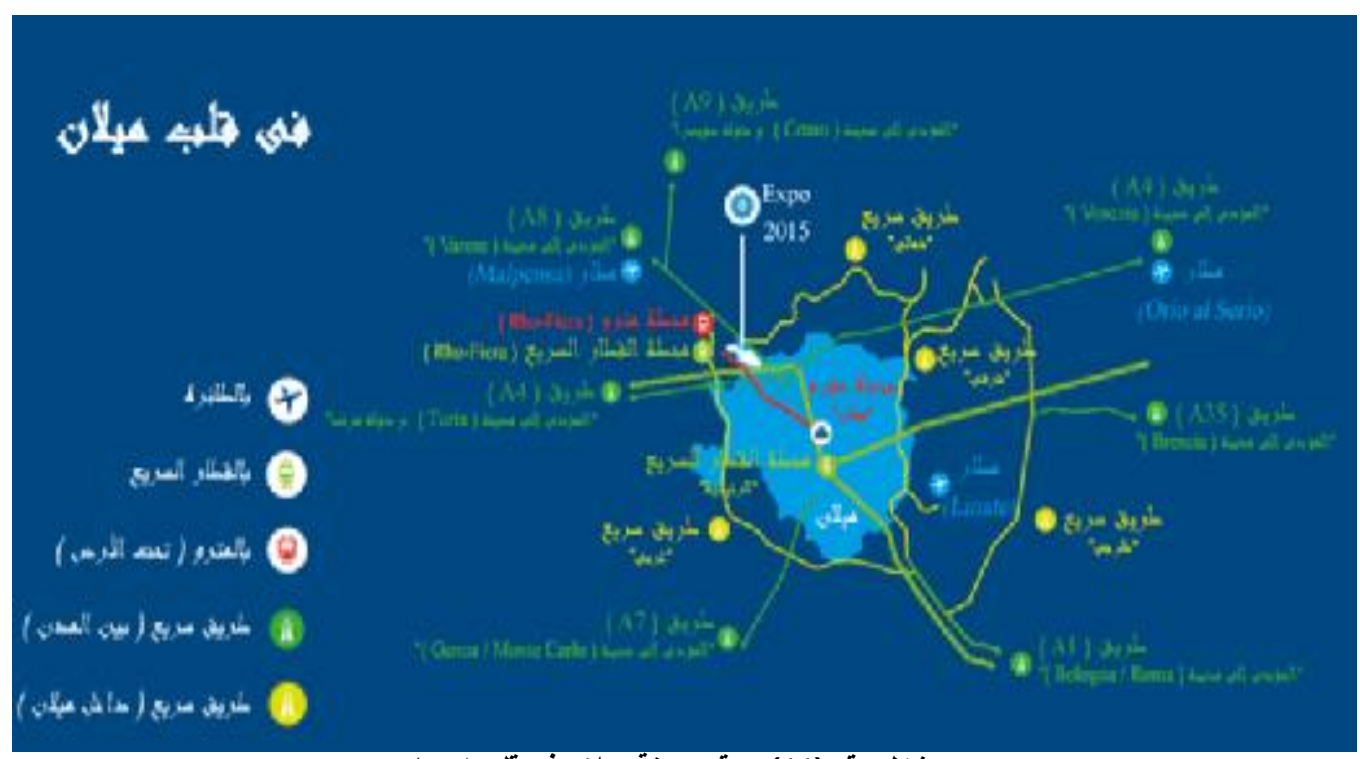

شكل رقم (11) موقع مدينة ميلان فى قلب اوربا

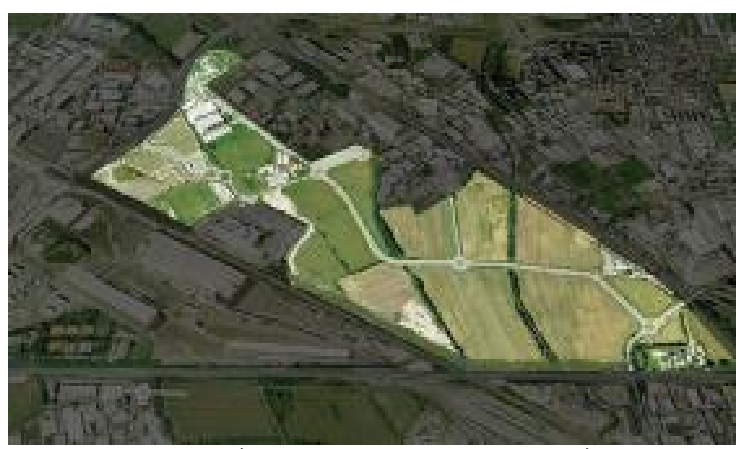

شكل رقم (12) يوضح ارض المعرض قبل بدء المشروع
التى تربط مدينة ميلان بالمدن الأخرى.

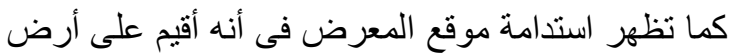

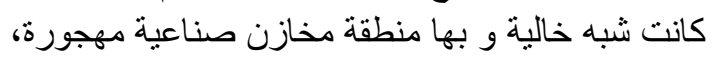
فقد تم تحويلها من مكان غير مستغل تخطيطياً ولا لا

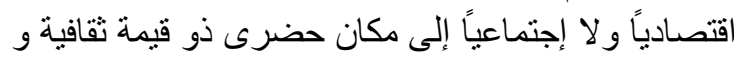

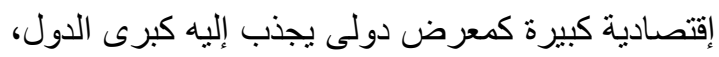

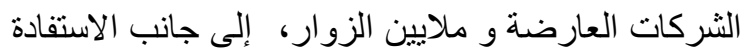

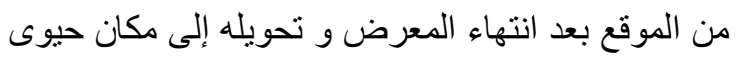
فى قلب مدينة ميلان ( العاصمة الإقتصادية لإيطاليا ). 


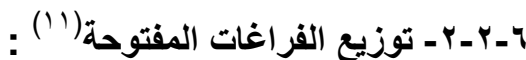

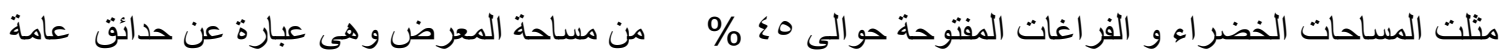

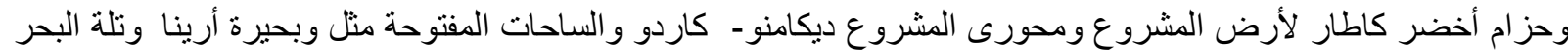

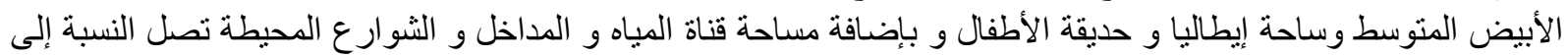

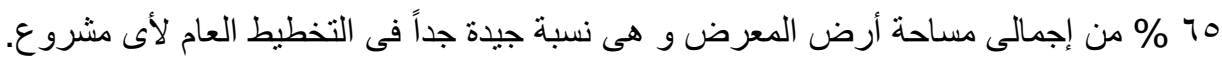

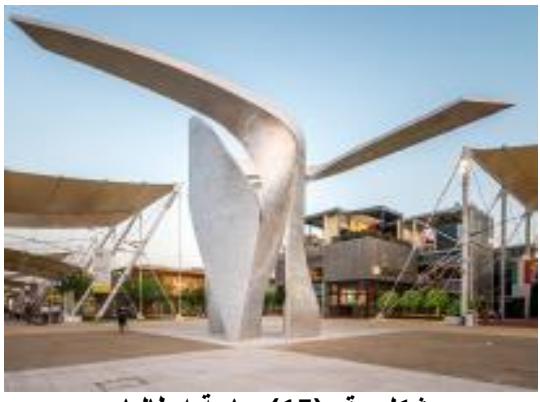

شكل رقم (15) ساحة ايطاليا

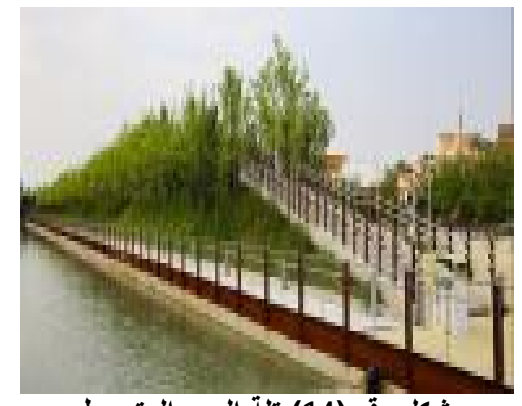

شكل رقم (14) تلة البحر المتوسط

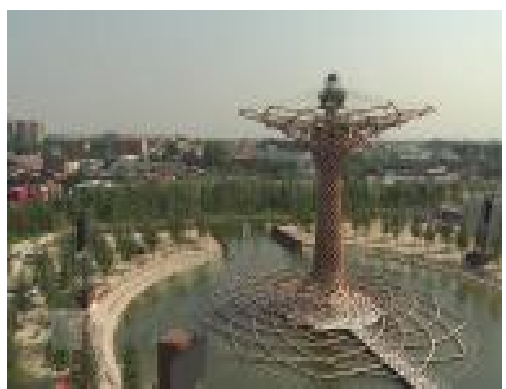

شكل رقم (13) بحيرة ارينا

و يظهر من توزيه المساحات الخضر اء بالمعرض مر اعاة مخططى المعرض على تطبيق الاستدامة فى تخطيطهم

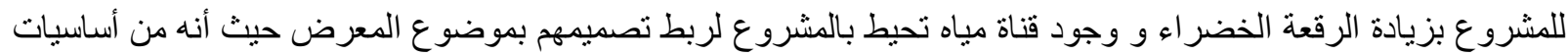

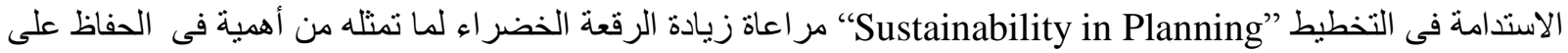

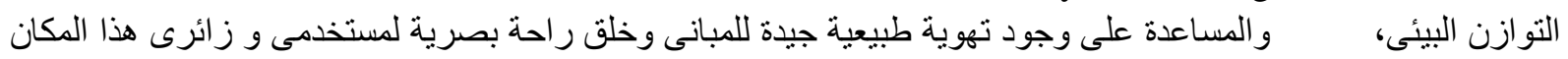

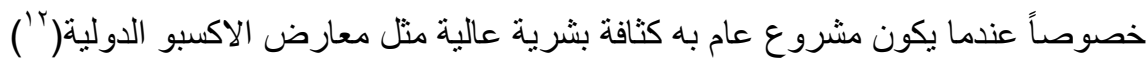

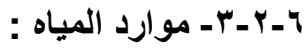

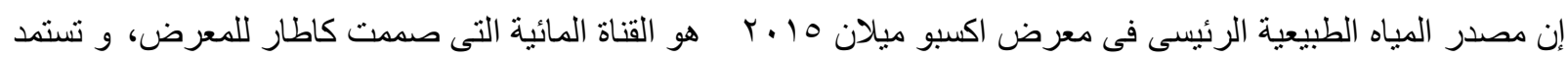

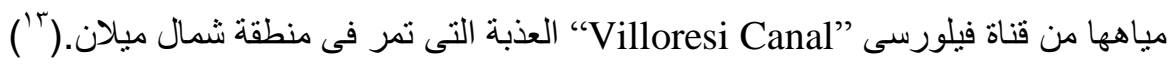

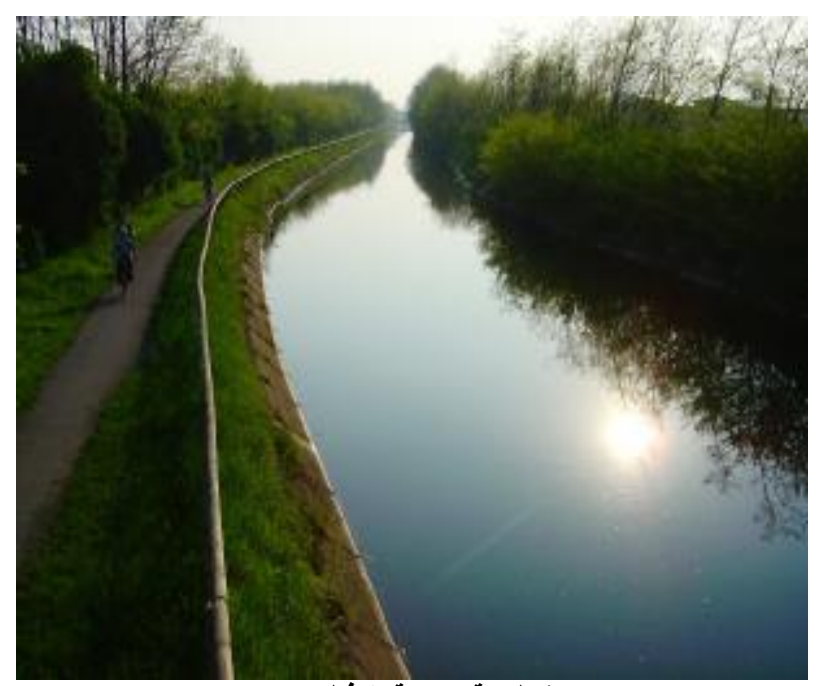

شكل رقم(17)قتناة فيلورسى

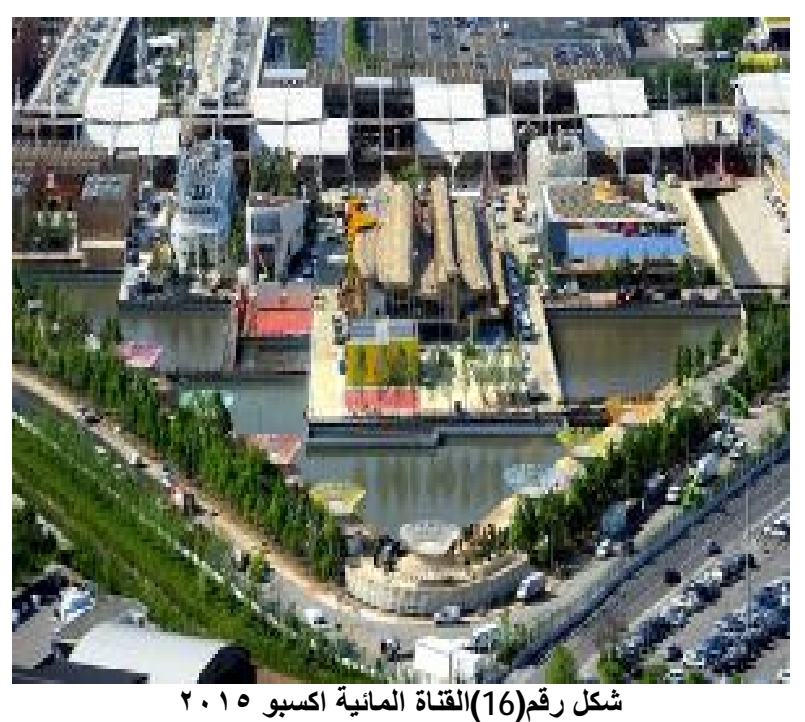


إن اختيار وضع قناة مائية تطوق أرض المعرض لم يكن مجرد فكرة تصميمية من مخططى المعرض لأهداف وظيفية و

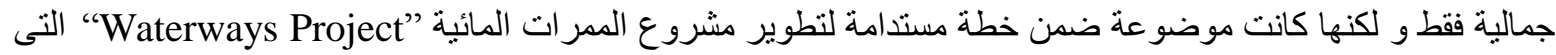

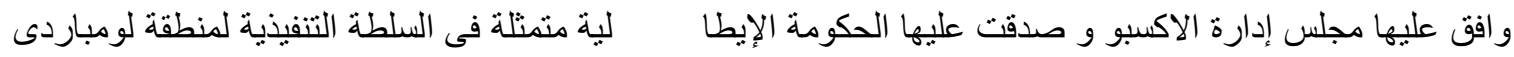

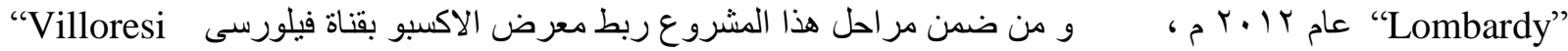

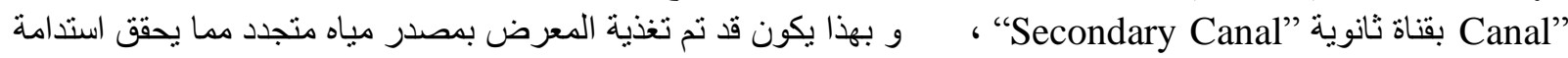

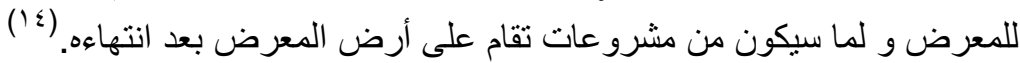

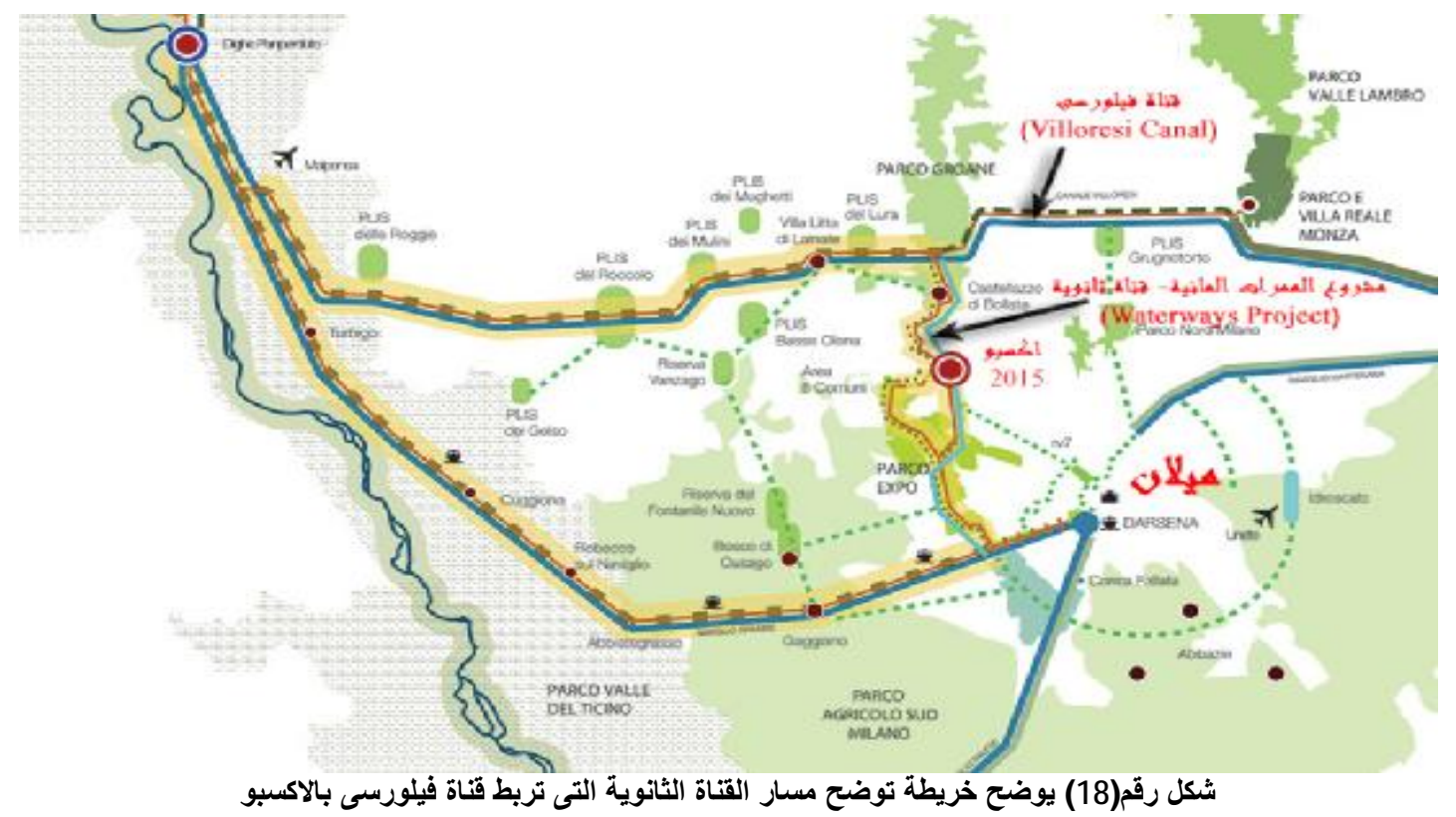


رصد تطبيقات الاستدامة فى تخطيط معارض الاكسبو الدولية (دراسة حالة معرض اكسبو ميلان 10 • Y)
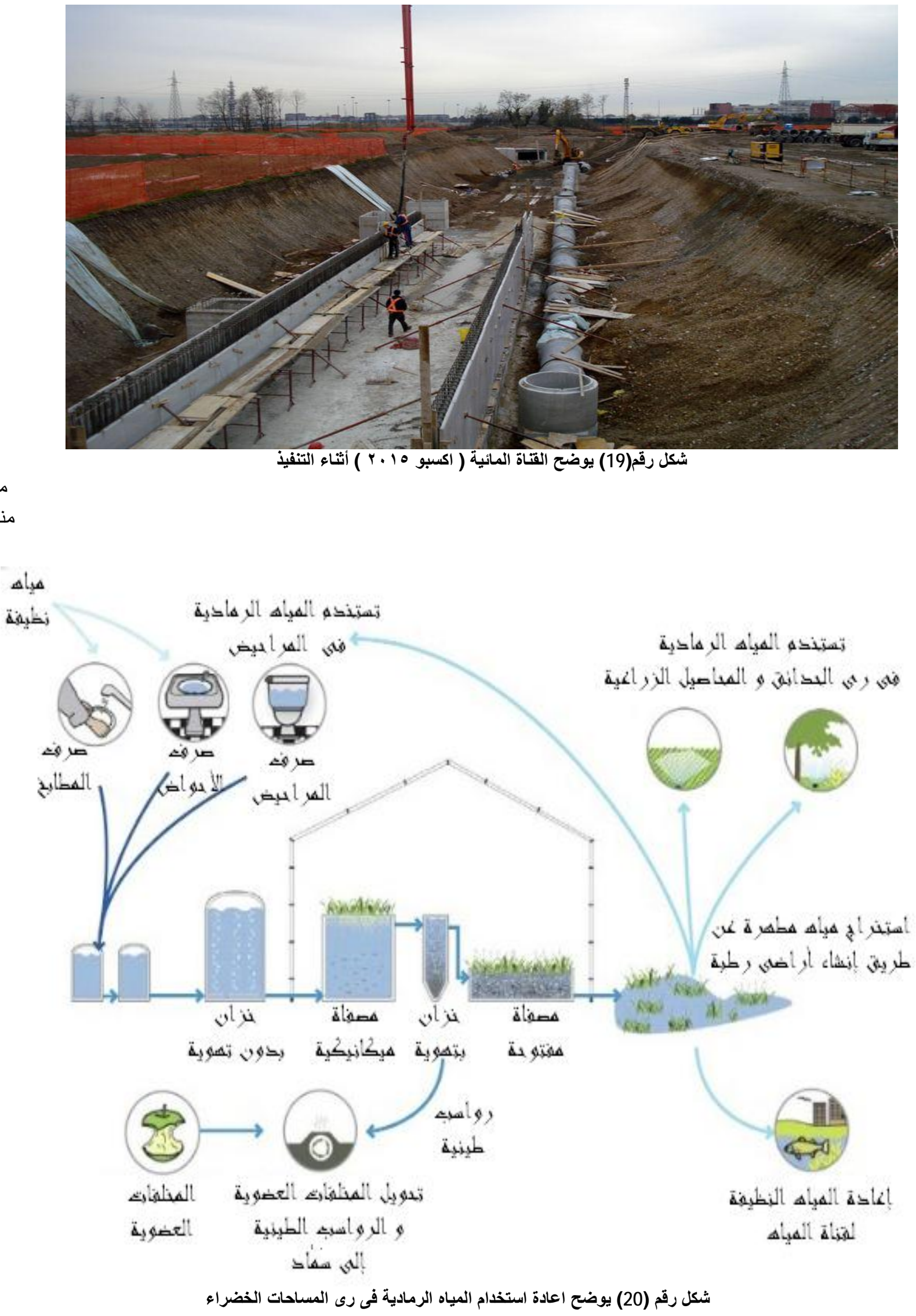
رصد تطبيقات الاستدامة فى تخطيط معارض الاكسبو الدولية (دراسة حالة معرض اكسبو ميلان 10 • Y)

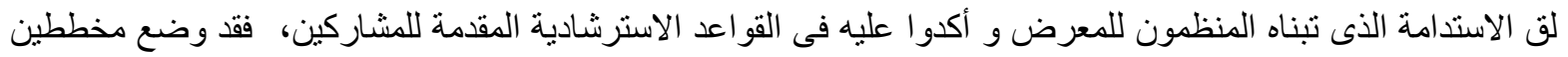

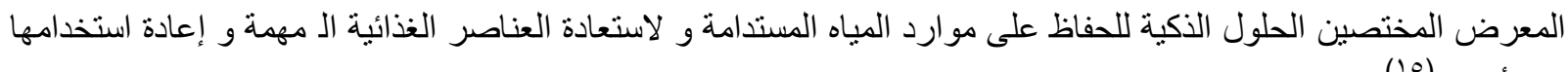

مرة أخرى (10).

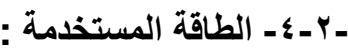

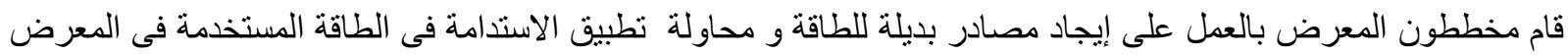

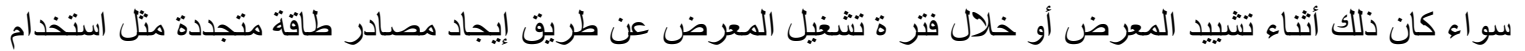

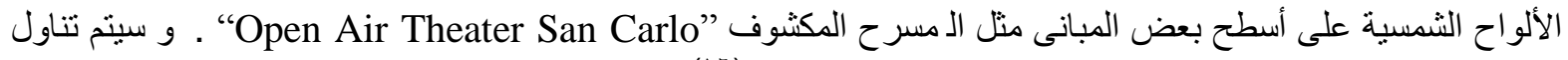

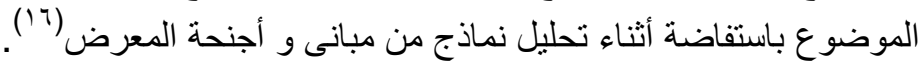




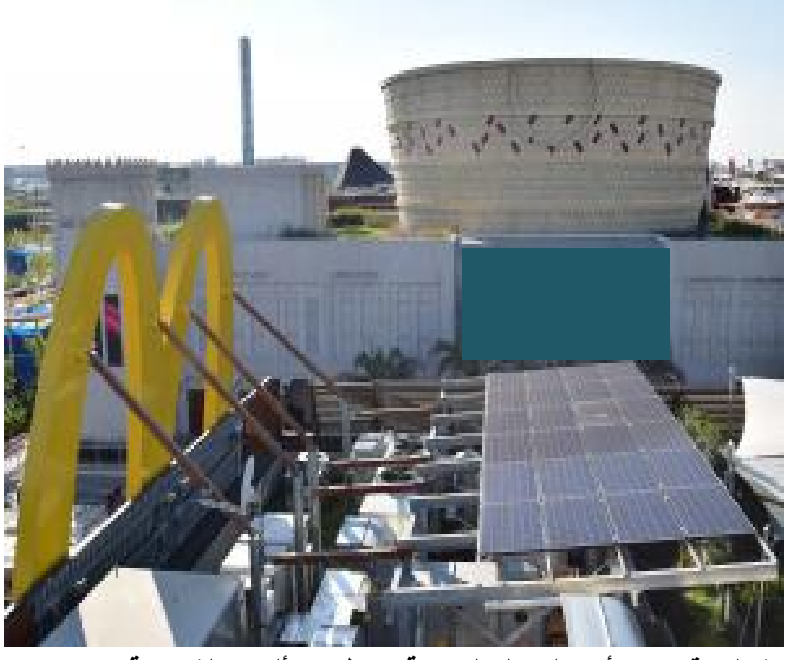

"Solar شكل رقم (22)أحد المحال الخدمية و تظهز الألواح الثمسية

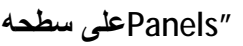

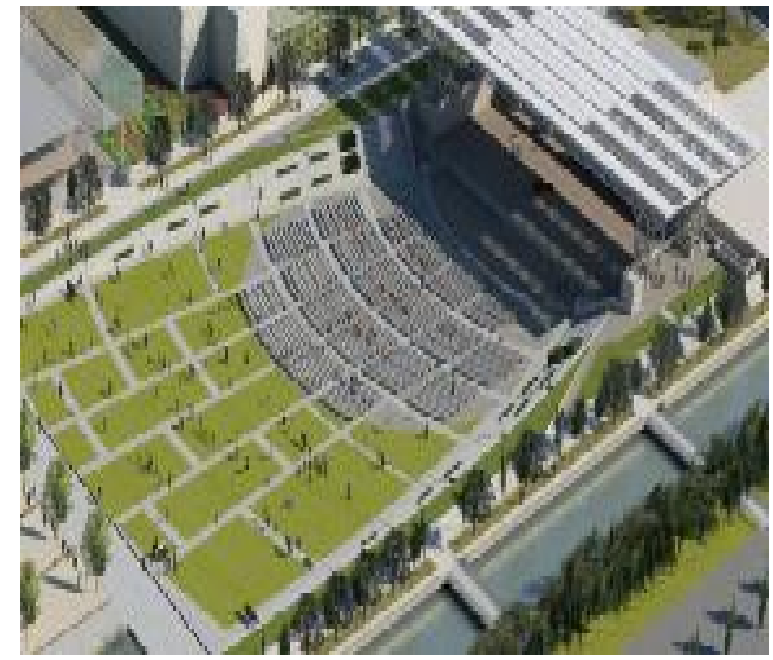

شكل رقم (21)مسرح "San Carlo" المكشوف و تظهر الألواح الثمسية "Solar Panels" على تغطية المسرح

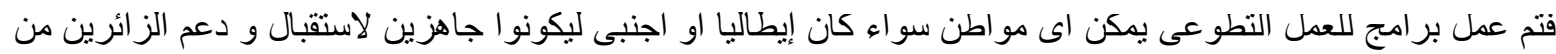

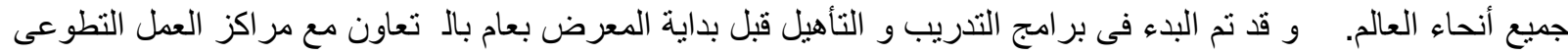

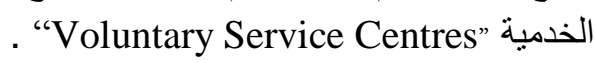

ד-Y - - - إدارة المخلفات و إعادة تدويرها (IV)

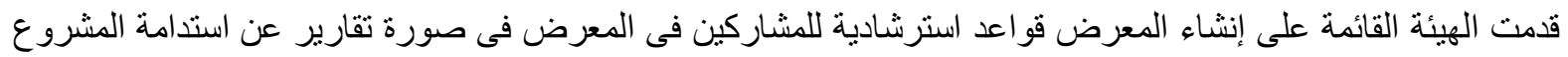

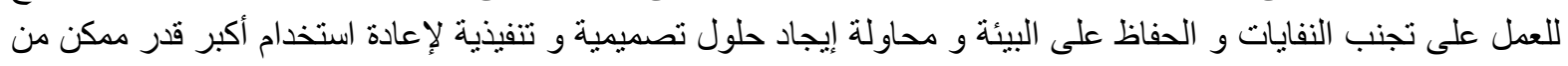
مكونات المبانى بعد الانتهاء من المعرض و إز الة المبانى. و يبين التحليل الموجود فى الأسفل الطريقة المثنالية للتقليل من

النفابات.

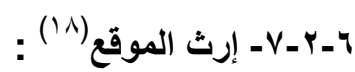

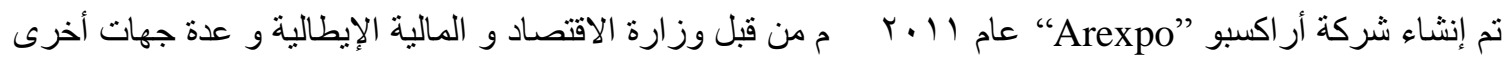

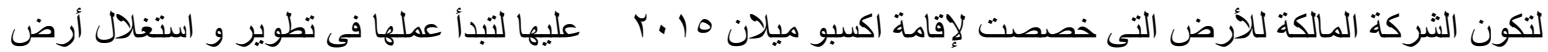

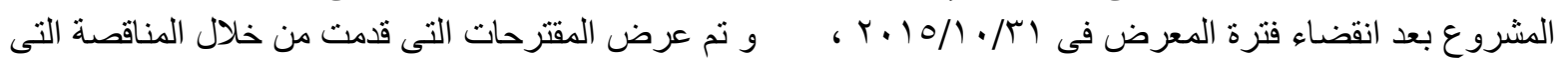

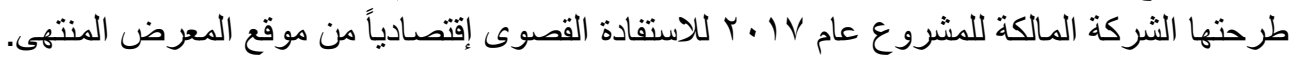




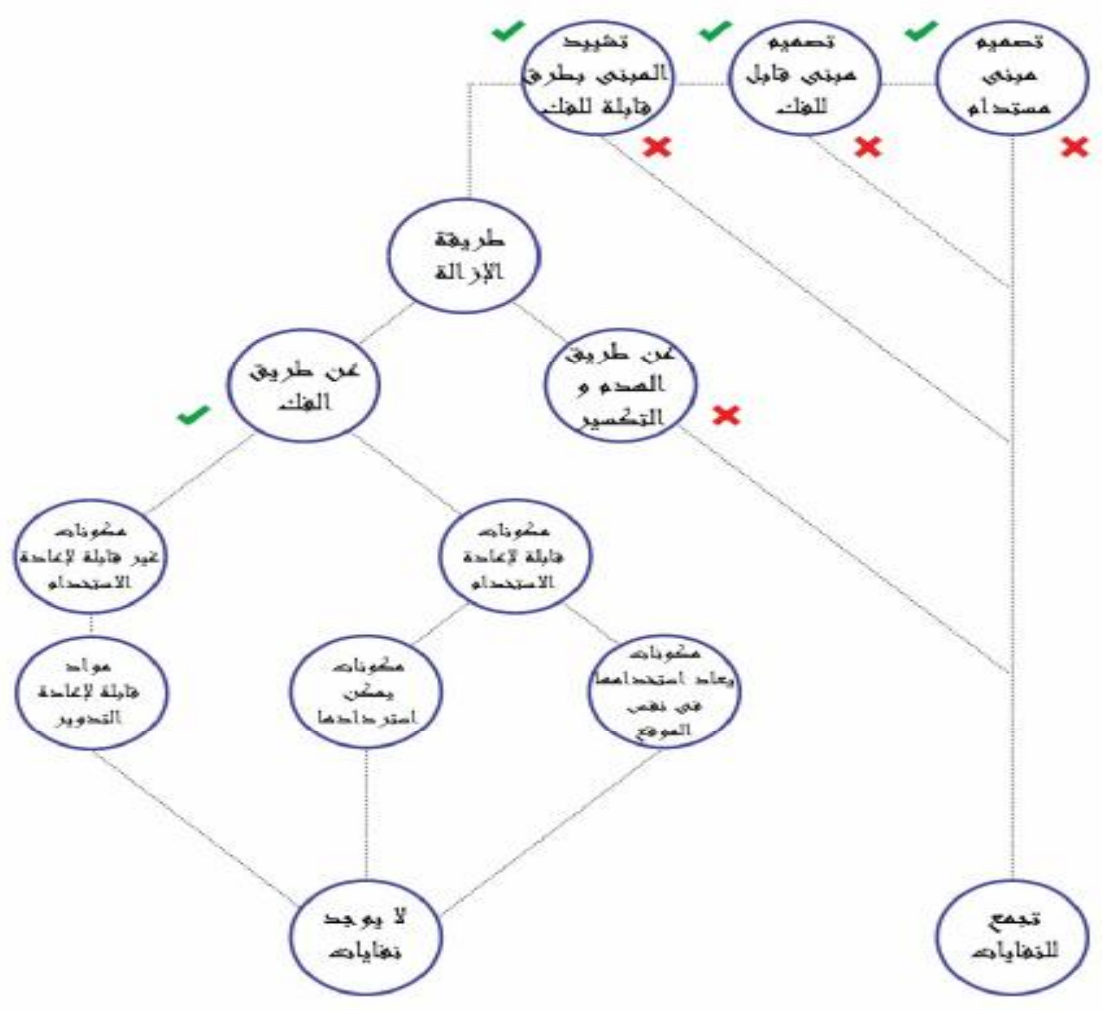

شكل رقم (23) طريقة التعامل مع النفايات فى معرض اكسبو ميلان

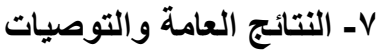

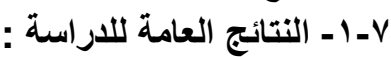

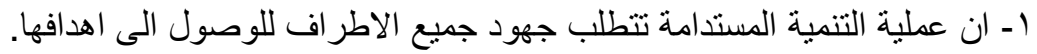

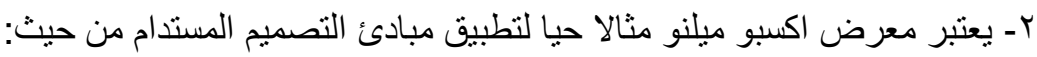

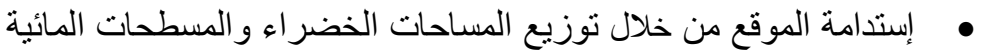

• • • • • • • • •

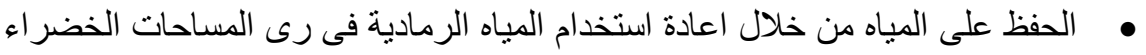

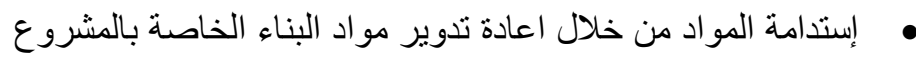

: r-V

ا - الإستفادة من الأبحاث و الدراسات التئى تقوم بها الجامعات و المر اكز البحثية وخاصة تللك الابحاث التى تتناول موضوع

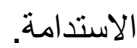

r- تفعيل المشاركة الثعبية بالمجهود و المال أو الأر اضى لتنفيذ مشرو عات التى تهدف الى التنمية المستدامة.

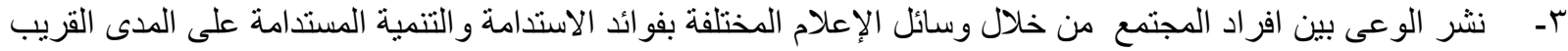
و البعيد وخاصة فيما يخص جو انب ترشيد الطاقة والم المحافظة على المياه 


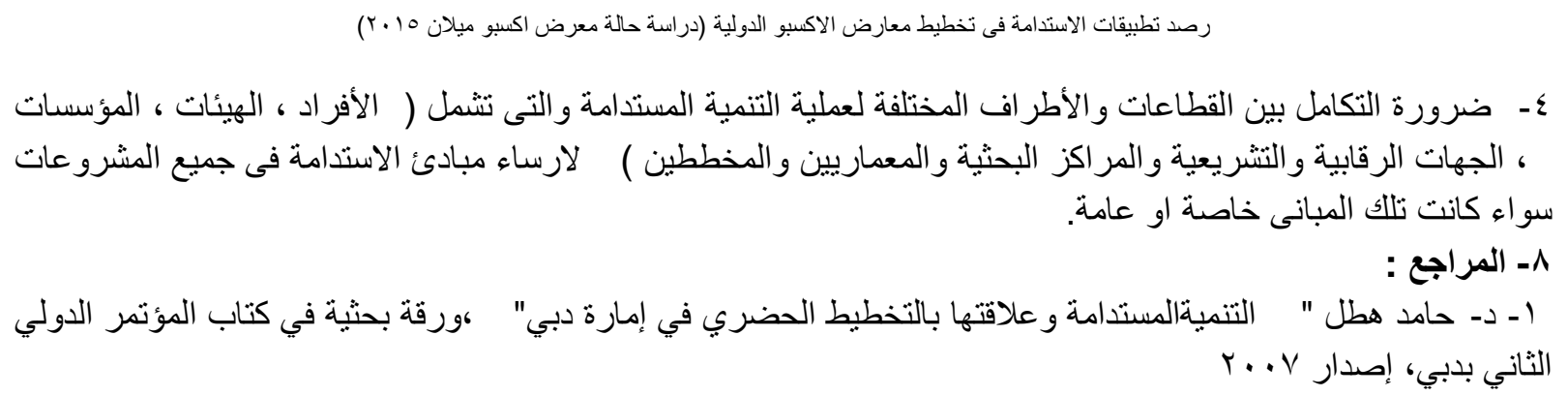

r - World Commission on Environment and Development, Our Common Future, pp. 4, Oxford University Press, New York, 1987.

3- (SABD) Sustainable Architecture and Building Design خطأ! مرجع الارتباط التشعبي غير صالح. by .Sam C M Hui.2002

4- Buildings and their Impact on the Environment, A Statistical Summary,US Archive Document, Revised April 2009

5- U.S. Environmental Protection Agency, web site, https://archive.epa.gov/greenbuilding/ web/html /about.html (active till 2017)

آ ـ د/ هيثم صـادق سليم ـ عمارة العولمة في مصر وغياب مفاهيم الاستدامة في التصميم "دراسة حالة المباني الإدارية بالقاهرة

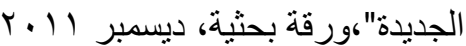

7- WBDG web site, National Institute of Building Sciences, http://www.wbdg.org/designobjectives/sustainable (active till 2017)

8- www.bie-paris.org/ Accessed May 2017.

9- www.expomuseum.com/ Accessed Jan 2018.

10- www.inexhibit.com/ Accessed Mars 2017.

11- www.milanworldsfair.com/ Accessed April 2016.

12- www.expo2015.org/ Accessed Dec 2016.

13- www.expo2015.org/archive/ Accessed Nov 2016.

14- www.expo2015plus100.org/ Accessed Feb 2017

15- www.dati.openexpo2015.it/ Accessed Sep 2016.

16- www.sustainableideas.it/ Accessed Aug 2017.

17- blog.urbanfile.org/ Accessed Jan 2017.

18- www.skyscrapercity.com/ Accessed Nov 2017.

19- expo2015-milano.blogspot.com/ Accessed Dec 2016.

20- www.platform-ad.com/ Accessed May 2016.

21- www.arexpo.it/ Accessed Jul 2017. 